


\title{
Probabilistic model for contamination of egg dishes with Salmonella spp. made from shell eggs produced on the island of Ireland
}

\author{
Louise Kelly $^{\mathrm{a}, \mathrm{b}}$, Laura Murchie ${ }^{\mathrm{c}}$, Bin Xia ${ }^{\mathrm{d}}$, Paul Whyte ${ }^{\mathrm{d}}$, Robert H. Madden ${ }^{\mathrm{c}, \mathrm{e}, *}$ \\ a Department of Statistics and Modelling Science, University of Strathclyde, Glasgow, G1 1XH, United Kingdom \\ ${ }^{\mathrm{b}}$ Centre for Epidemiology and Risk Analysis, Veterinary Laboratories Agency, New Haw, Addlestone, Surrey, United Kingdom \\ c Food Science Department, Queen's University of Belfast, Belfast, BT9 5PX, United Kingdom \\ d Centre for Food Safety, School of Agriculture, Food Science and Veterinary Medicine, University College Dublin, Dublin, Ireland \\ ${ }^{\text {e }}$ Food Microbiology Branch, Agri-Food and Biosciences Institute, Belfast, BT9 5PX, United Kingdom
}

Keywords:

Quantitative exposure assessment

Salmonella

Eggs

Ireland

\begin{abstract}
A B S T R A C T
A quantitative model was constructed to estimate the probability that a serving of food containing eggs produced on the island of Ireland is contaminated with Salmonella spp. The model is based on the prevalence of contaminated eggs at the time of lay and a set of parameters which describe the pooling of eggs in the home and in catering situations. Both external and internal contamination of the eggs by Salmonella spp. was considered. The model estimates that there is a $90 \%$ chance that the probability of a serving of food being contaminated is between $0.0043 \%$ and $0.038 \%$. Sensitivity analysis demonstrated that egg prevalence drives this low probability and that, at the current level of egg prevalence at the time of lay, pooling of eggs has a minor effect. These results indicate the importance of maintaining the low prevalence of contaminated eggs at the time of lay to minimise the risk of human cases of salmonellosis from consumption of eggs.
\end{abstract}

\section{Introduction}

The role of eggs in the increase in human cases of Salmonella enteritidis reported in many countries in the 1980 90s is well acknowledged (Coyle et al., 1988; St Louis et al., 1988; Cowden et al., 1989a,b; de Louvois, 1993a,b). Recent years have seen a decline in the reported incidence of human salmonellosis in the Republic of Ireland (Foyle et al., 2004) and in cases of S. Enteritidis PT4 in England and Wales (Anonymous, 2008b), Scotland (Anonymous, 2007a) and Northern Ireland (NI) (Anonymous, 2008a). This may be a reflection of the lower prevalences of eggs contaminated by Salmonella as demonstrated by recent surveys of eggs in the UK (Anonymous, 2004; Anonymous, 2007b; Elson et al., 2005) and the island of Ireland (Anonymous, 2003; Murchie et al., 2007).

The reductions in the prevalence of eggs contaminated by Salmo nella coincide with the introduction of legislation, industry codes of practice and quality assurance schemes (Cogan and Humphrey, 2003), which were introduced in the late 1990s in both the UK and Ireland to achieve this end. Throughout the European Union, including the Republic of Ireland and NI, the control of Salmonella spp. in the egg

\footnotetext{
* Corresponding author. Food Microbiology Branch, Agri-Food \& Biosciences Institute, Newforge Lane, Belfast, BT9 5PX, United Kingdom. Tel.: +44 2890 255312; fax: +442890255009.

E-mail address: r.madden@qub.ac.uk (R.H. Madden).
}

production chain is governed by the European Union Zoonoses Directive (Council Directive 92/117/EEC). In the Republic of Ireland the directive is transposed into Irish law as S.I. No. 2 of 1996 (Anonymous, 1996) under which all hatcheries, poultry breeder farms and laying flocks are monitored for Salmonella spp. and any flocks confirmed with $S$. enteritidis or S. typhimurium are slaughtered. In addition, both feed materials and feedstuffs for poultry are tested for Salmonella spp. Treatment of laying flocks with vaccines, antibiotics or competitive exclusion type products is forbidden.

In addition to the Directive, voluntary schemes are operated in both the Republic of Ireland and NI. In NI, the Lion Quality code of practice, which requires the vaccination of commercial layer flocks against $S$. enteritidis, has been widely adopted (Anon, 2009), with approximately $85 \%$ of UK egg production covered by the scheme. The Bord Bia Egg Quality Assurance Scheme is a voluntary programme in the Republic of Ireland which incorporates additional Salmonella spp. controls to those specified in legislation. The scheme reiterates the ban on the treatment of laying flocks with vaccines, antibiotics or competitive exclusion type products, hence the scheme differs significantly from that employed in NI.

Although different control strategies are employed in NI and the Republic of Ireland a survey of eggs produced on the island of Ireland found no statistically significant difference in the prevalence of salmonellae in eggs produced under the two regimes (Murchie et al., 2007) and that the prevalence was very low in both jurisdictions. These 
results seem to indicate that the measures employed in the two jurisdictions are equally effective in the control of Salmonella spp. in eggs.

In recent years, microbiological risk assessment (MRA) has become an important tool in the management of food borne hazards. Assessments have been undertaken for Campylobacter (Hartnett et al., 2002; Rosenquist et al., 2003), Salmonella (Whiting \& Buchanan, 1997; Whiting et al., 2000; Anonymous, 2002a; Hope et al., 2002), Listeria monocytogenes (Sanaa et al., 2004) and Escherichia coli 0157:H7 (Cassin et al., 1998) among others. To assess the risk posed by Salmonella spp. in eggs on the island of Ireland, two exposure assessments were deemed necessary. Firstly, a qualitative exposure assessment, to provide initial guidance to risk managers on the probability of exposure to, and probable levels of, Salmonella in egg containing foods was completed (Murchie et al., 2008). Secondly, a quantitative assessment was undertaken, with the primary aim of investigating the effects of changes to some of the parameters that had been identified as important in driving the qualitative probability of exposure. In this paper, we present the quantitative model and the effects of changes to the key parameters.

\section{Materials and methods}

\subsection{Model overview}

The assessment estimates the probability that a random serving of an egg containing meal is contaminated with Salmonella $\left(P_{\text {serv }}\right)$. The same pathway as that used in the qualitative assessment of Murchie et al. (2008) is considered and thus covers three stages:

(a) production and packing

(b) distribution and storage

(c) preparation and consumption

The probability $P_{\text {serv }}$ was estimated from the prevalence of contaminated eggs at the time of lay, modified to account for possible pooling of eggs when they are prepared for consumption. It was assumed that there would be several consumption pathways, as outlined by Murchie et al. (2008). Some of these pathways would result in complete removal of Salmonella, e.g. complete removal as a result of adequate cooking. Due to the fact that consumption pathway data for the island of Ireland were very limited, it was decided not to model the pathways individually and instead to consider the "average" situation. By doing this, the effect of prevalence reduction is removed and thus was not modelled. This may result in an over estimate of prevalence compared to the situation where pathways are modelled individually.

The model relates to eggs produced on the island of Ireland only; imported eggs are not included. Uncertainty is incorporated in model inputs and thus outputs take the form of probability distributions. Monte Carlo simulation (10,000 iterations) using the software package @RISK (@ Palisade), was used to generate the probability distributions.

\subsection{Prevalence of contaminated eggs}

The model commences with estimation of the prevalence of Salmonella spp. in shell eggs at the time of lay. The estimate is based on data obtained from a survey of eggs produced on the island of Ireland conducted from March 2005 to April 2006 (Murchie et al., 2007). The survey reported a low prevalence of Salmonella, with only two of 5018 samples of six eggs being positive. Both isolates were obtained from the shells of eggs only; no contents were found to contain Salmonella. The risk associated with Salmonella on the shells of eggs was not modelled explicitly; prevalence of Salmonella was estimated from the level of egg contamination reported, which included shell contamination. This therefore over estimated the prevalence.
The probability that an individual sample of six pooled eggs (the sampling unit tested in the egg survey) is positive for Salmonella $(P)$ is calculated from Eq. (1)

$P=X / N$

where $X$ is the number of positive samples and $N$ is the number of samples tested.

Assuming a binomial process for sampling, and that each egg is independent and has the same probability of being contaminated, the probability of all $K$ eggs in a pool being negative is given by Eq. (2)

$\left(1-P_{\text {egg }}\right)^{K}$

where $P_{\text {egg }}$ is the probability that an individual egg is positive. The probability that an individual pooled sample is positive is therefore given by Eq. (3)

$P=1-\left(1-P_{\text {egg }}\right)^{K}$

Equating Eqs. (1) and (3) and re arranging gives

$P_{\text {egg }}=1-(1-X / N)^{1 / K}$

A beta distribution was used to describe the uncertainty associated with the estimate of sample prevalence. Therefore, using the survey data (Murchie et al., 2007), the probability that an individual egg is contaminated is described by

$P_{\text {egg }}=1-(1-\operatorname{beta}(X+1, N-X+1))^{1 / K}$

with $X=2, N=5018$, and $K=6$.

\subsection{The effect of pooling}

The practice of pooling eggs during food preparation can increase the probability of a serving being contaminated. Pooling refers to the mixing of several eggs together; the resulting mixture is then used to prepare multiple food servings. The presence of a single contaminated egg in the pool results in the contamination of all portions of food prepared from the pool. To account for this, the probability $P_{\text {egg }}$ was adjusted to give the probability $P_{\text {serv }}$. It was assumed that this probability would not change during subsequent steps of the exposure pathway because cross contamination was not considered (hence no increase in prevalence) and at least one of the possible consumption pathways could involve uncooked eggs (hence, overall, no decrease in prevalence).

The likelihood of pooling depends on whether eggs are prepared at home or in catering situations. There are no data available on the proportions of eggs used in domestic as compared to catering settings for the island of Ireland, but in the Republic of Ireland and the UK (Anonymous, 2007b) it was estimated that approximately two thirds of shell eggs were destined for the retail market. These data suggest that the proportion of eggs consumed in domestic and catering situations are similar throughout the island of Ireland. This value was used to estimate the probability of an egg being prepared in the home, $P_{\text {home }}=0.66$. Pert distributions were used to define the probabilities of pooling in the home and in catering establishments, $P_{\mathrm{hp}}=\operatorname{pert}(0 \%, 2 \%, 10 \%)$ and $P_{\mathrm{cp}}=\operatorname{pert}(2 \%, 5 \%, 20 \%)$, and the number of eggs pooled in the home when pooling occurs, $N_{\mathrm{h}}=\operatorname{pert}(2,4,12)$. A uniform distribution was used to estimate the number of eggs pooled in catering establishments when eggs are pooled, $N_{\mathrm{c}}=$ uniform $(6,48)$. Pooling data were not available for the island of Ireland; the parameters of the pert and uniform distributions were those used in the MRA developed by USDA FSIS (Anonymous, 1998). 
When an individual egg is pooled, the number of contaminated eggs in the pool was assumed to follow a binomial distribution. Hence, the probabilities of the home and catering produced pools being contaminated with Salmonella are given by Eqs. (6) and (7) respectively

$P_{\mathrm{hpc}}=1-\left(1-P_{\mathrm{egg}}\right)^{N_{\mathrm{h}}}$

$P_{\mathrm{cpc}}=1-\left(1-P_{\text {egg }}\right)^{N_{c}}$

The probability $P_{\text {serv }}$ is then given by Eq. (8)

$$
\begin{aligned}
P_{\text {serv }}= & P_{\text {home }}\left(P_{\mathrm{hp}} P_{\mathrm{hpc}}+\left(1-P_{\mathrm{hp}}\right) P_{\text {egg }}\right) \\
& +\left(1-P_{\text {home }}\right)\left(P_{\mathrm{cp}} P_{\mathrm{cpc}}+\left(1-P_{\mathrm{cp}}\right) P_{\text {egg }}\right)
\end{aligned}
$$

\subsection{Sensitivity analysis}

The qualitative exposure assessment concluded that there is a low probability of exposure to Salmonella spp. from consuming foods containing eggs produced on the island of Ireland. It also concluded that the negligible prevalence of contaminated eggs at the time of lay was important in keeping this probability low and that pooling was one factor that may increase the likelihood of exposure through the production chain. To investigate the effects of both prevalence at lay and pooling more thoroughly, we set all uncertain inputs to their mean values and then modified the parameters $X$, the number of positive samples in the egg survey, $N_{\mathrm{h}}$, the number of eggs pooled in the home and $N_{\mathrm{c}}$ the number of eggs pooled in catering situations, as shown in Table 1 . For $X$, the range investigated has a maximum value equal to the number of samples tested in the egg survey, thus corresponding to $100 \%$ sample prevalence. For $N_{\mathrm{h}}$ and $N_{\mathrm{c}}$ the maximum values were arbitrarily chosen, extending just beyond the maximum of the pert distribution used for pooling in catering situations.

All parameters were initially modified individually from their baseline values and then the parameter $X$ was modified in conjunction with $N_{\mathrm{h}}$ and $N_{\mathrm{c}}$ individually to determine the combined effects of prevalence and pooling. The combined effects were measured as the percentage increase in $P_{\text {serv }}$ over the range of $N_{\mathrm{h}}$ and $N_{\mathrm{c}}$ values.

\section{Results}

\subsection{Baseline model}

The probability density function (pdf) describing the uncertainty associated with $P_{\text {serv }}$ is illustrated in Fig. 1 . The mean value is 0.000169 and the median is 0.000151 , so the distribution is slightly skewed. The 5th and 95th percentiles indicate that there is a $90 \%$ chance that between $0.0043 \%$ and $0.038 \%$ of food servings containing eggs produced on the island of Ireland will be contaminated with Salmonella spp.

\subsection{Sensitivity analysis}

Fig. 2 illustrates the effect that the number of positive samples of six eggs has on $P_{\text {serv }}$. The effect is initially linear and then there is an

Table 1

Parameter values used in the sensitivity analysis.

\begin{tabular}{lll}
\hline Parameter & Baseline value & Range \\
\hline$X$ & 2 (value reported in egg survey) & 1 to 5018 \\
$N_{\mathrm{h}}$ & 5 (mean of pert distribution) & 1 to 50 \\
$N_{\mathrm{c}}$ & 27 (mean of pert distribution) & 1 to 50 \\
\hline
\end{tabular}

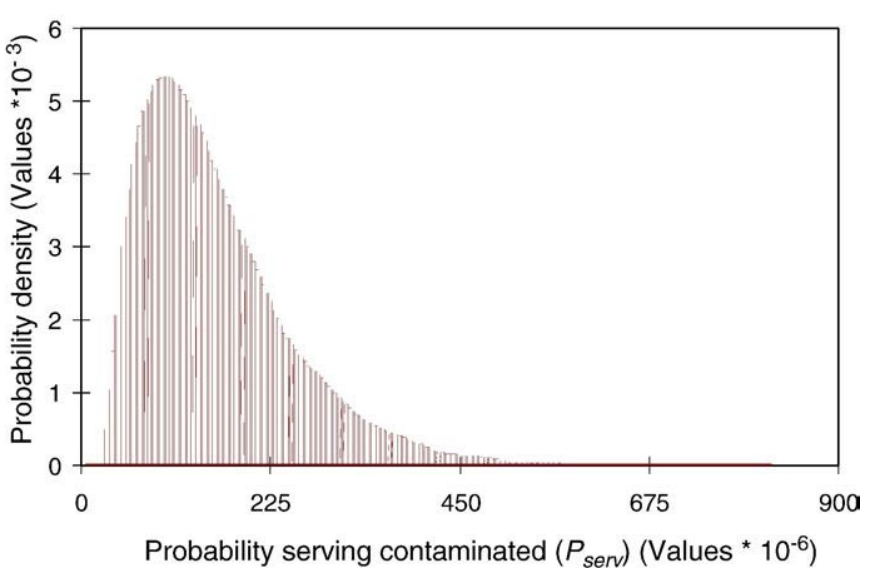

Fig. 1. Probability density function describing the uncertainty associated with the probability that a serving of food containing eggs produced on the island of Ireland is contaminated with Salmonella.

exponential increase in $P_{\text {serv }}$ from around 26\% (when $X=4000$ ) to $100 \%$ (when $X=5018$ ).

In Fig. 3, the baseline effects of the numbers of eggs pooled in the home and in catering situations on $P_{\text {serv }}$ are demonstrated for the current level of egg prevalence $(X=2)$; in both cases the effect is linear, when $N_{\mathrm{h}}$ and $N_{\mathrm{c}}$ are varied individually from one to 50 . The absolute increases in $P_{\text {serv }}$ are very small e.g. if the number of eggs pooled in the home is increased from one (no pooling) to an unrealistic value of $50, P_{\text {serv }}$ only increases by 0.00006 . However, if the percentage increases over this range are considered, more noticeable effects are observed. Table 2 gives the percentage increases relative to the case when there is no pooling ( $N_{\mathrm{h}}$ and $N_{\mathrm{c}}$ set to one); with the current level of positive egg prevalence, $P_{\text {serv }}$ increases by, respec tively, $59 \%$ and $107 \%$ as $N_{\mathrm{h}}$ and $N_{\mathrm{c}}$ are increased from one to 50 (Table 2). The effect of increasing the number of eggs pooled is reduced as the number of positive samples, and thus estimated positive egg prevalence, is increased; for $X=4000$, which represents a positive egg prevalence of $26 \%$ (from Eq. (4)), the increase in $P_{\text {serv }}$ is only $6 \%$ and $7 \%$ for home and catering pooling respectively (Table 2 ). Figs. 4 and 5 demonstrate the effects of pooling for higher positive egg prevalence ( $X=1000$ and $X=4000$, respectively). As $X$ increases, the effect of the number of eggs pooled on $P_{\text {serv }}$ becomes non linear; for very high prevalence adding additional eggs to the pool will not increase the likelihood of exposure. The most important effects occur when egg prevalence is at a "medium" level; for $X=1000$, represent ing an egg prevalence of $4 \%$ (Eq. (4) and Table 2), $P_{\text {serv }}$ increases by, respectively, $32 \%$ and $49 \%$ when the number of eggs pooled in the home and in catering situations are increased from one to 50. The differences between the effects of pooling in the home and in catering situations also diminish as positive egg prevalence increases.

\section{Discussion}

The quantitative results presented here are in broad agreement with the qualitative exposure assessment for the same population and source of eggs (Murchie et al., 2008): the probability of exposure to Salmonella spp. from consumption of eggs produced on the island of Ireland is low and the low prevalence of contaminated eggs is the key factor in maintaining this situation. The qualitative assessment also suggested that pooling was an additional important factor for exposure, however, the quantitative results indicate that, in the current situation, the effect is minor compared with the effect of egg prevalence; when egg prevalence is low, the resulting probability of contamination is low, irrespective of the number of eggs pooled, and 


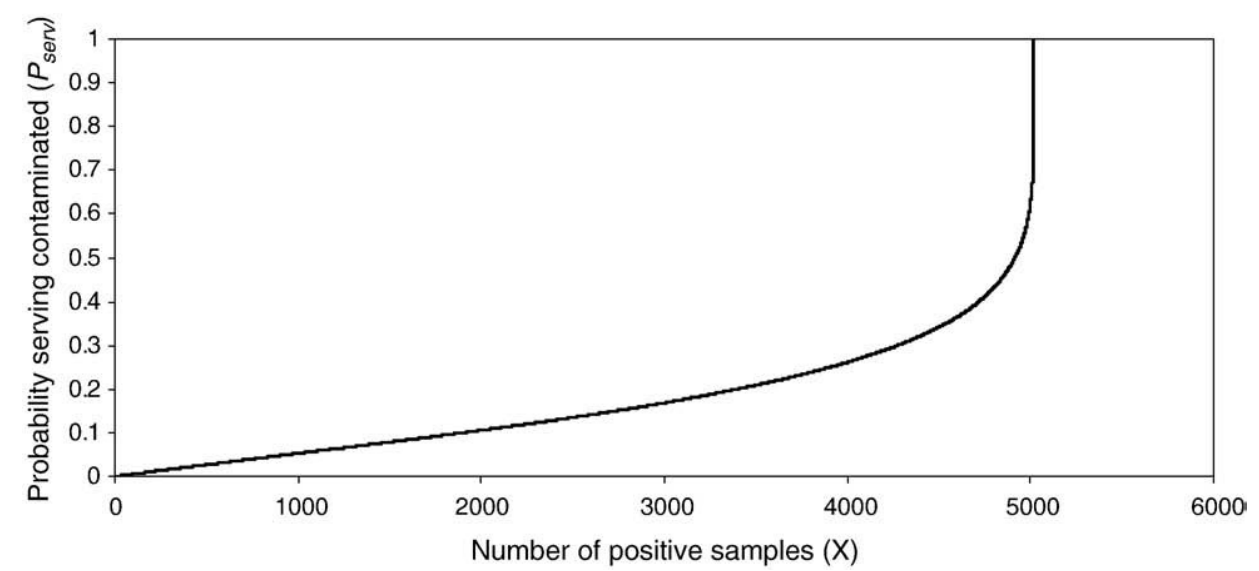

Fig. 2. Effect of the number of positive samples $(X)$ on the probability a serving is contaminated $\left(P_{\text {serv }}\right)$.

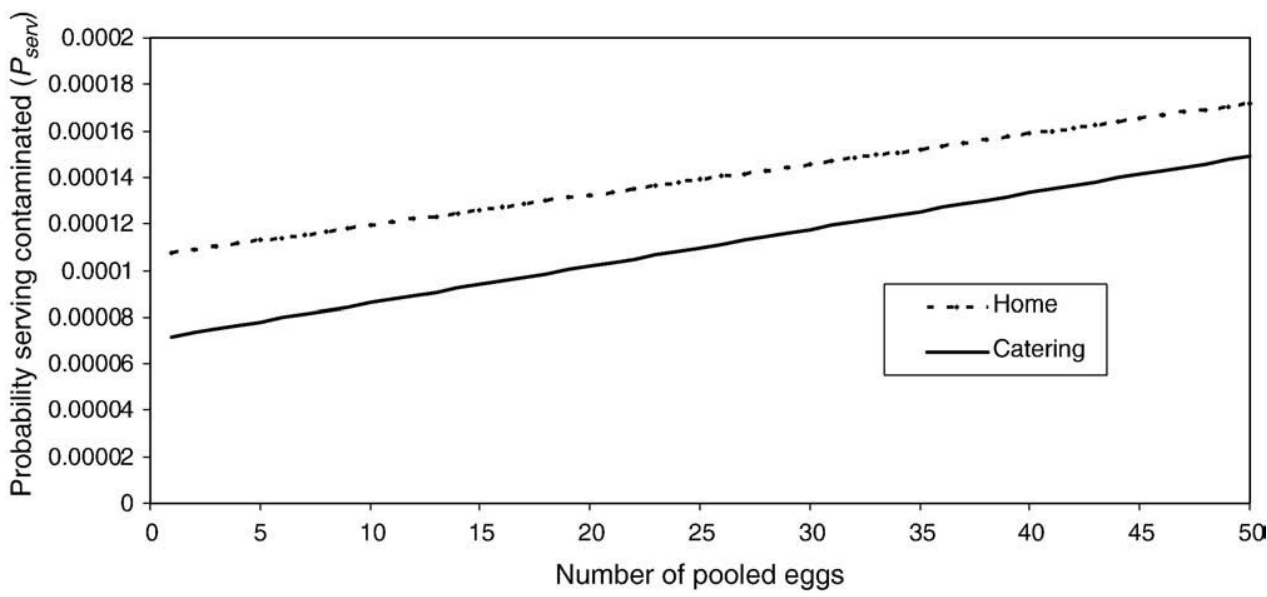

Fig. 3. Effects of the number of eggs pooled at home $\left(N_{\mathrm{h}}\right)$ and in catering situations $\left(N_{\mathrm{c}}\right)$ on the probability a serving is contaminated $\left(P_{\text {serv }}\right)$ with the number of positive samples $X=2$.

when egg prevalence is high, the resulting probability of contamina tion is also high and changes very slightly as the number of eggs pooled is increased. Egg prevalence can therefore currently be used as a good indicator of the likelihood of exposure. It is worth noting, however, that were egg prevalence to increase to a "medium" level, pooling would become more important.

As suggested by CAC (1999), exposure assessments should provide an estimate of the probability of exposure and an estimate of the number of organisms to which a consumer is exposed. The number of organisms ingested can be estimated by modelling changes in the number per egg/serving from the point of lay until the time of consumption. Changes will be determined by growth and decline, both of which will depend on time and temperature profiles. In addition, different preparation methods will influence numbers, for example, whether the eggs are eaten as an egg meal or as ingredients to other food products. Detailed modelling of the Salmonella exposure pathway for eggs has been undertaken by FAO/WHO (Anonymous, 2002a). This full MRA was based mainly on North American data. We were unable to obtain access to equivalent time/temperature and preparation data for the island of Ireland and therefore we did not update the FAO/WHO estimates to obtain a full MRA for the island of Ireland. Given the current low level of prevalence at the time of lay, it is unlikely that these factors would influence the conclusions generated from this simple parsimonious model; attempting to model them without data would only add unnecessary uncertainty.
We did, however, use the FAO/WHO model to obtain an idea of the order of magnitude of the numbers to which consumers would be exposed: the suggested level was between 1 and 2 organisms per serving, on average. Using this level in the dose response model proposed by FAO/WHO (Anonymous, 2002a) and combining the result with our estimated average value of $P_{\text {serv }}$ suggests that the risk of illness per consumption event would be around $0.000002 \%$. The low value of $P_{\text {serv }}$ has a large effect on this risk.

The estimation of prevalence in Eq. (4) is based on the sampling framework used in the egg survey from which the prevalence data were obtained (Murchie et al., 2007). In the survey, the sampling unit

Table 2

The combined effects of the number of positive samples $(X)$ and the number of eggs pooled at home $\left(N_{\mathrm{h}}\right)$ and in catering situations $\left(N_{\mathrm{c}}\right)$ on the probability of exposure $\left(P_{\text {serv }}\right) ; N_{\mathrm{h}}$ is varied over the range $(1,50)$ while $N_{\mathrm{c}}$ is set at 27 and $N_{\mathrm{c}}$ is varied over the range $(1,50)$ while $N_{\mathrm{h}}$ is set at 5 .

\begin{tabular}{llll}
\hline$X$ & $P_{\text {egg }}(\%)$ & \multicolumn{2}{l}{ Percentage increase in $P_{\text {serv }}$} \\
\cline { 3 - 4 } & & $N_{\mathrm{h}}$ varied $(\%)$ & $N_{\mathrm{c}}$ varied $(\%)$ \\
\hline 2 & 0.01 & 59 & 107 \\
10 & 0.03 & 59 & 107 \\
100 & 0.3 & 56 & 99 \\
1000 & 4 & 32 & 49 \\
4000 & 23 & 6 & 7 \\
\hline
\end{tabular}




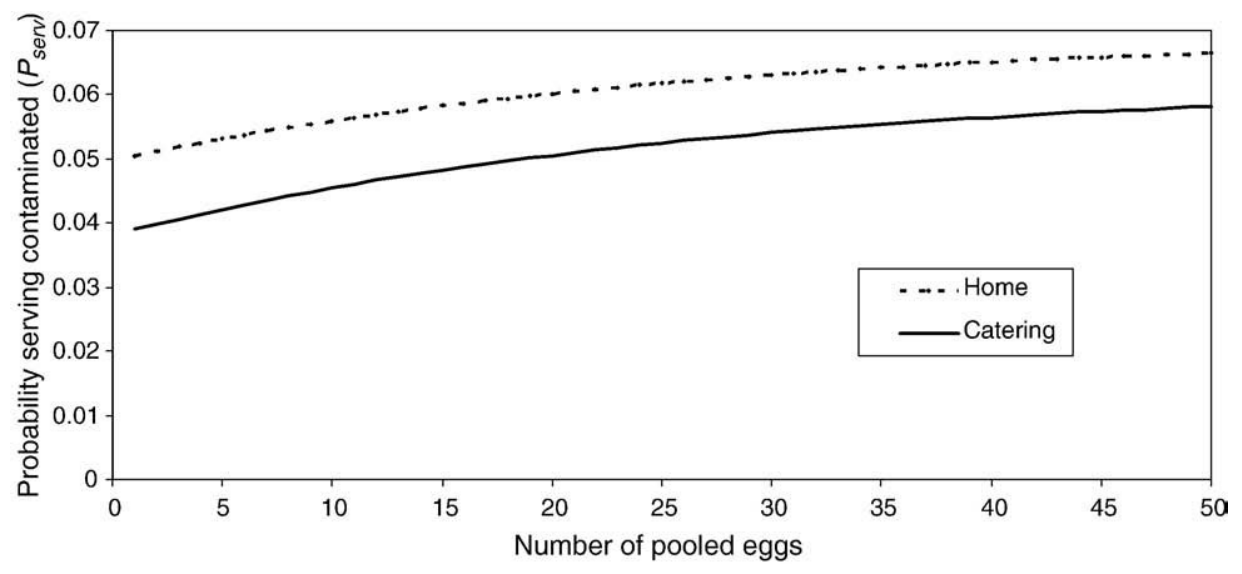

Fig. 4. Effects of the number of eggs pooled at home $\left(N_{\mathrm{h}}\right)$ and in catering situations $\left(N_{\mathrm{c}}\right)$ on the probability a serving is contaminated $\left(P_{\text {serv }}\right)$ with the number of positive samples $X=1000$.

was six pooled eggs and the corresponding egg prevalence for which the exponential increase in $P_{\text {serv }}$ begins is around $26 \%(X=4000$ in Eq. (4)). This phase of exponential increase will not provide reliable predictions for $P_{\text {egg }}$ and thus $P_{\text {serv }}$ because the biological relevance will be lost; for example if $X=5018, P_{\text {egg }}$ is $100 \%$, which will not be true if some eggs in the pool of six are not contaminated. The exponential phase will be shorter, and thus the predictions more accurate, for smaller values of the sample pool size $(K)$. In addition, the model assumes that eggs in the pooled sample are independent. In cases of high prevalence, the assumption of independence is unlikely to hold. Although these limitations exist, they are only important under a high prevalence scenario and because prevalence is currently low, the model gives reliable predictions. Should an increase in prevalence be observed, it would be important to reformulate both the sampling strategy and the model.

At the current low level of egg prevalence at the time of lay, pooling has a limited effect on the probability of a serving being contaminated. Were prevalence to increase, pooling would become more important, with the probability of contamination increasing as the number of eggs in the pool increases. However, should prevalence become very high, pooling would again become less important than prevalence at the time of lay.

The probability model given by Eq. (8) assumes that the probability of exposure will not increase or decrease throughout the egg production chain. Increases in prevalence may occur due to organisms present on the shell penetrating to egg contents, and from cross contamination during preparation, while decreases will result from adequate cooking. Given the current low prevalence of contaminated eggs, it is unlikely that these factors will have any significant effect on exposure. However, should prevalence increase, it would be important to include these factors. To do this would require preparation data specific to the island of Ireland. Such data are not currently available and thus any more complicated model would include much more uncertainty.

Only eggs laid and produced on the island of Ireland were considered in this probability model as the assessment is based on production and prevalence data for $\mathrm{NI}$ and the Republic of Ireland. The true estimate of $P_{\text {serv }}$ may therefore be higher when considering the total consumption of eggs on the island of Ireland, as a minority of these eggs may have originated from other countries. Eggs imported to the UK from certain EU countries have been found to have a higher prevalence of S. enteritidis (Little et al., 2006) and imported eggs have been linked to increases in the incidence of human Salmonella cases (Anonymous, 2002b).

In conclusion, the probability model presented in this paper has demonstrated that consumers of eggs produced on the island of Ireland have around a $0.01 \%$ chance of exposure to Salmonella each time they consume food containing eggs; their risk of illness will be much lower than this and is heavily influenced by the probability of exposure. It is important that all efforts are made to maintain the low prevalence of contaminated eggs and thus maintain this low level of exposure.

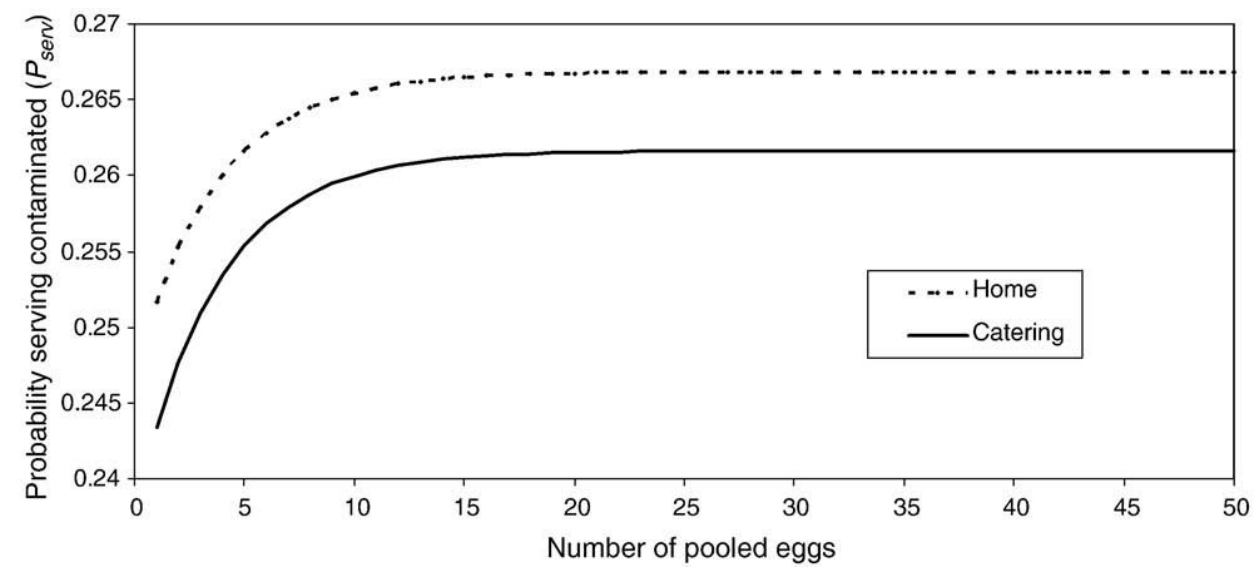

Fig. 5. Effects of the number of eggs pooled at home $\left(N_{\mathrm{h}}\right)$ and in catering situations $\left(N_{\mathrm{c}}\right)$ on the probability a serving is contaminated $\left(P_{\text {serv }}\right)$ with the number of positive samples $X=4000$. 


\section{Acknowledgements}

This study was funded by safefood, the Food Safety Promotion Board, as project 03 RESR 005.

\section{References}

Anonymous, 1996. S.I. No 2/1996. European Communities (Zoonoses) Regulation 1996. Available at: http://www.irishstatutebook.ie/ZZSI2Y1996.html. Accessed 16 June 2009.

Anonymous, 1998. Salmonella enteritidis risk assessment. Shell eggs and egg products. Final Report. Prepared for FSIS by the Salmonella Enteritidis Risk assessment Team. Available as PDF at: http://www.fsis.usda.gov/ophs/risk/ Accessed 16 June 2009.

Anonymous, 2002b. Salmonella enteritidis outbreaks in England and Wales, September to November 2002. CDR Weekly 12 (49)

Anonymous, 2002a. Risk assessments of Salmonella in eggs and broiler chickens. Microbiological risk assessment series 2. World Health Organization, Geneva, Switzerland; Food and Agriculture Organization of the United Nations, Rome, Italy.

Anonymous, 2003. Results of Third Quarter National Survey 2003 (03NS3) Bacteriological Safety of Eggs Produced Under the Bord Bia Egg Quality Scheme (EQAS). Food Safety Authority of Ireland, Dublin, Ireland. Available at: http://www.fsai.ie/uploadedFiles/ Monitoring_and_Enforcement/Monitoring/Surveillance/eggs_bacteriological.pdf. Accessed 16 June 2009

Anonymous, 2004. Report of the survey of Salmonella contamination of UK produced shell eggs on retail sale. Food Standards Agency, HMSO, London, UK. Available at: http://www.food.gov.uk/science/surveillance/fsis2004branch/fsis5004eggs. Accessed 16 June 2009.

Anonymous, 2007a. Annual Data Table Salmonella. Health Protection Scotland, Glasgow, UK Available at: http://www.documents.hps.scot.nhs.uk/giz/10-year-tables/salmonella. pdf. Accessed 16 June 2009.

Anonymous, 2007b. UK wide survey of Salmonella in raw shell eggs used in catering premises. Final Report. Food Standards Agency. Available at: http://www.food.gov. uk/multimedia/pdfs/eggsurvey2007.pdf. Accessed 16 June 2009.

Anonymous, 2008a. Laboratory Reports of Salmonella Enteritidis 1995-2005, Northern Ireland. Communicable Disease Surveillance Centre Northern Ireland, Belfast, UK Available at: http://www.cdscni.org.uk/surveillance/Gastro/Salmonella_sp.htm. Accessed 16 June 2009.

Anonymous, 2008b. Salmonella enteritidis in Humans, Faecal and Lower Gastrointestina Tract Isolates, England and Wales, 1981-2006. Health Protection Agency, London, UK Available at: http://www.hpa.org.uk/web/HPAweb\&HPAwebStandard/HPAweb_C/ 1195733804697. Accessed 16 June 2009.

Anonymous, 2009. Summary of Lion Quality code of practice. British Egg Industry Council. BEIS, London, UK. Available at: http://lioneggs.co.uk/page/lionmark. Accessed 8 September 2009.

CAC, Codex Alimentarius Commission, 1999. Principles and Guidelines for the Conduct of a Microbiological Risk Assessment. FAO, Rome. CAC/GL-30.

Cassin, M.H., Lammerding, A.M., Todd, E.C.D., Ross, W., McColl, R.S., 1998. Quantitative risk assessment for Escherichia coli 0157: H7 in ground beef hamburgers. International Journal of Food Microbiology 41, 21-44.

Cogan, T.A., Humphrey, T.J., 2003. The rise and fall of Salmonella enteritidis in the UK. Journal of Applied Microbiology 94, 114S-119S.
Cowden, J.M., Chisholm, D., O'Mahony, M., Mawer, S.L., Spain, G.E., Ward, L., Rowe, B. 1989a. Two outbreaks of Salmonella enteritidis phage type 4 infection associated with the consumption of fresh shell-egg products. Epidemiology and Infection 103 , 47-52.

Cowden, J.M., Lynch, D., Joseph, C.A., O'Mahony, M., Mawer, S.L., Rowe, B., Bartlett, C.L., 1989b. Case-control study of infections with Salmonella enteritidis phage type 4 in England. British Medical Journal 299, 771-773.

Coyle, E.F., Palmer, S.R., Ribeiro, C.D., Jones, H.I., Howard, A.J., Ward, L., Rowe, B., 1988. Salmonella enteritidis phage type 4 infection: association with hens' eggs. Lancet 332 (8623), 1295-1297.

de Louvois, J., 1993a. Salmonella contamination of eggs. Lancet 342 (8867), 366-367.

de Louvois, J., 1993b. Salmonella contamination of eggs: a potential source of human salmonellosis. PHLS Microbiology Digest 10, 158-162.

Elson, R., Little, C.L., Mitchell, R.T., 2005. Salmonella and raw shell eggs: results of a cross-sectional study of contamination rates and egg safety practices in the United Kingdom catering sector in 2003. Journal of Food Protection 68, 256-264.

Foyle, B., McKeown, P., Doran, G., Cormican, M., 2004. Annual report on Salmonella in Ireland, 2004. National Disease Surveillance Centre, Dublin, Ireland. Available at: http://www.ndsc.ie/hpsc/A-Z/Gastroenteric/Salmonellosis/Publications/File,1461,en. pdf. Accessed 16 June 2009.

Hartnett, E., Kelly, L.A., Gettinby, G., Wooldridge, M., 2002. A quantitative risk assessment for Campylobacters in broilers: work in progress. International Biodeterioration and Biodegradation 50, 161-165.

Hope, B.K., Baker, R. Ebel, E.D. Hogue, A.T. Schlosser, W.D. Whiting R. McDowell, R.M. Morales, R.A., 2002. An overview of the Salmonella enteritidis risk assessment for shell eggs and egg products. Risk Analysis 22, 203-218.

Little, C.L., Walsh, S., Hucklesby, L., Surnan_Lee, S., Pathak, K., Hall, Y., dePinna, E., Threfall, E.J., Maund, A., Chan, C.-H., 2006. Survey of Salmonella contamination of non-UK produced shell eggs on retails sale in the North West of England and London. Final Report. Food Standards Agency. Available at: http://www.food.gov. uk/news/pressreleases/2006/nov/surveyeggs. Accessed 16 June 2008.

Murchie, L., Whyte, P., Xia, B., Horrigan, S., Kelly, L., Madden, R., 2007. Prevalence of Salmonella in Grade A whole shell eggs in the island of Ireland. Journal of Food Protection 70, 1238-1240.

Murchie, L., Xia, B., Madden, R., Whyte, P., Kelly, L., 2008. Qualitative exposure assessment for Salmonella spp. in shell eggs produced on the island of Ireland. International Journal of Food Microbiology 125, 308-319.

Rosenquist, H., Nielsen, N.L., Sommer, H.M., Norrung, B., Christensen, B.B. 2003. Quantitative risk assessment of human campylobacteriosis associated with thermophilic Campylobacter species in chickens. International Journal of Food Microbiology $83,87-103$.

Sanaa, M., Coroller, L., Cerf, O., 2004. Risk assessment of listeriosis linked to the consumption of two soft cheeses made from raw milk: Camembert of Normandy and Brie of Meaux. Risk Analysis 24, 389-399.

St Louis, M.E., Morse, D.L., Potter, M.E., DeMelfi, T.M., Guzewich, J.J., Tauxe, R.V., Blake, P.A The Salmonella enteritidis Working Group, 1988. Journal of the American Medical Association 259, 2103-2107.

Whiting R.C. Buchanan, R.L. 1997. Development of a quantitative risk assessment model for Salmonella enteritidis in pasteurized liquid eggs. International Journal of Food Microbiology 36, 111-125.

Whiting, R.C., Hogue, A., Schlosser, W.D., Ebel, E.D., Morales, R.A., Baker, A., McDowell, R.M. 2000. A quantitative process model for Salmonella enteritidis in shell eggs. Journal of Food Science 65, 864-869. 